\title{
ANALYSIS ON FLOW AND HEAT TRANSFER PERFORMANCE OF CUO NANO-FLUID
}

\author{
Sahib Singh ${ }^{1}$, Gautam Kocher ${ }^{2}$ \\ ${ }^{I}$ Research Scholar, Department of Mechanical Engineering, Ramgariha Institute of Engineering \& Technology, \\ Punjab, India \\ ${ }^{2}$ Head of the Department, Department of Mechanical Engineering, Ramgariha Institute of Engineering \& Technology, \\ Punjab, India
}

\begin{abstract}
Heat exchangers are widely used in the heat transfer applications where heat to be rejected or inserted by the system or in to the system. Since past few decades, researchers have found that the rate of heat transfer can be enhance during nano-fluids as they are having better thermophysical properties compared to conventional fluids. Using Two-Step Method, a nano-fluid has been prepared by adding $\mathrm{CuO}$ particles into distilled water. The arrangement has been done in such a way that the hot fluid (hot water and nano-fluid) flows through inner pipe and cold water is flowing through the outer pipe. It was detected that the convective heat transfer has improved when $\mathrm{CuO}-\mathrm{H}_{2} \mathrm{O}$ nanofluid was used instead of water.
\end{abstract}

Keywords: - Thermophysical properties, Nano-fluid, Nano-particles, Pressure drop, and Heat Transfer.

\section{INTRODUCTION}

Heat exchangers play a principalpart in heat transfer applications and are widely employed in food and chemical processing industries, manufacturing industries, refrigeration and air conditioning industries, space applications etc. Various methods have been used till date in order to enhance the heat transfer rates. The active method includes electrohydrodynamics, jets, sprays, ultrasound waves, synthetic jet heat transfer and high amplitude vibratory motion, while passive method includes a surface coating, Nanoscale coating, nanofluid, hydrodynamic cavitation's, turbulence promoters and mixing promoters. Since past few decades, researchers have found that the rate of heat transfer can be enhanced using nano-fluids as they are having better thermophysical properties compared to conventional fluids [1]. Kim et al. [2] have performed experiments on double pipe heat exchanger under laminar flow conditions in order to study the heat transfer coefficient of transformer oil with alumina nanoparticles flowing through a circular pipe and the authors have found a significant enhancement in the heat transfer coefficient. Wongwises et al. [3] have studied theoretically and experimentally, the forced convective heat transfer coefficient (h) of Nanofluids and they concluded that the dispersed nanoparticles increase the thermal conductivity of the base fluids owing their riotous association, there by turbulence and fluctuations of the base fluid increases which speeds up the energy exchange process. Goodarzi et al., [4] experimentally investigated pressure drop and heat transfer in a corrugated plate countered flow heat exchanger using multi-walled carbon nanotube Nanofluids. They found that the thermal characteristics of the Nanofluid were greater than the base fluid water. This could be due to growth in
Reynolds number and increase in volume fraction of Nanoparticles. Darzi et al. [5] experimentally investigated the effect of $\mathrm{SiO}_{2}-\mathrm{H}_{2} \mathrm{O}$ Nanofluid on flow characteristics and turbulent heat transfer coefficient inside helically corrugated tubes. The results showed that increasing corrugation height and decreasing corrugation pitch increases the heat transfer [6-10].

Therefore to add further towards the development of increasing the thermal performance of heat exchangers using nanofluids, a double pipe heat exchanger with inner pipe spirally corrugated have been used for the study. The nanofluid used was $\mathrm{CuO}-\mathrm{H}_{2} \mathrm{O}$ of $0.05 \%$ volume concentration. The idea of this work is to examine the effect on flow behavior and heat transfer characteristics experimentally of a double pipe heat exchanger.

\section{METHODOLOGY}

The main components of Corrugated Double pipe Heat exchanger (CDPHE) include inner Spirally Corrugated Pipe (Stainless Steel) of 30mm diameter, Outer Pipe (Mild Steel) of $50 \mathrm{~mm}$ diameter, pumps, PVC pipes, rubber tubes, immersion rod, and storage tank. The hot fluid is allowed through the inner pipe while cold fluid is delivered through the outer pipe. Two cases have been investigated in order to ensure the effect of Nanofluids on the $h\left(\mathrm{~W} / \mathrm{m}^{2} \mathrm{~K}\right)$ in a countered flow heat exchanger arrangement.

Experiment-I: In the first case water at temperature ranges from $323-328 \mathrm{~K}$ is passed through the inner pipe while cold water is passed through an outer pipe at room temperature. 
Experiment-II: In the second case, $\mathrm{CuO}-\mathrm{H}_{2} \mathrm{O}$ nanofluid was prepared using distilled water through two-way methods and $\mathrm{CuO}$ nanoparticles comprising volume concentration of $0.05 \%$ have been introduced in the hot water $(323-330 \mathrm{~K})$ which is flowing through the inner pipe while in the outer pipe cold water is flowing at temperature ranges from293-298K.

Table 1: Properties of Water and Nanofluid

\begin{tabular}{|l|l|l|}
\hline Property & Water & $\begin{array}{l}\text { Nanofluid(CuO- } \\
\left.\mathbf{H}_{2} \mathbf{O}\right)\end{array}$ \\
\hline Density $\left(\mathrm{kg} / \mathrm{m}^{3}\right)$ & 994 & 1261 \\
\hline Specific Heat $(\mathrm{J} / \mathrm{kgK})$ & 4190 & 3305 \\
\hline $\begin{array}{l}\text { Thermal Conductivity } \\
(\mathrm{W} / \mathrm{m}-\mathrm{K})\end{array}$ & 0.8 & 0.9 \\
\hline $\begin{array}{l}\text { Kinematic Viscosity } \\
\left(\mathrm{m}^{2} / \mathrm{s}\right)\end{array}$ & $0.78 \mathrm{E}-03$ & $0.46 \mathrm{E}-06$ \\
\hline
\end{tabular}

Table 2: Velocities used for the experimental investigation

\begin{tabular}{|l|l|}
\hline Water Velocity $(\mathbf{m} / \mathbf{s})$ & Nanofluid Velocity $(\mathbf{m} / \mathbf{s})$ \\
\hline 0.16 & 0.36 \\
\hline 0.2 & 0.45 \\
\hline 0.26 & 0.52 \\
\hline 0.29 & 0.66 \\
\hline
\end{tabular}

The fluid was heated using an immersion rod and to measure the volumetric flow rate of both the fluids, flow sensor was used. 13grams of $\mathrm{CuO}$ nanoparticle are being dispersed in 4litres of base fluid (water). The properties of pure water and nanofluid are tabulated in Table 1 . Table 2 represents the velocities values for the flow of water and nanofluid. The weight of nanoparticle is calculated by using the formula given below:

Figure 2 (a) represents the variation of Reynolds number with volume flow rate. It has been found that Reynolds number is more in $\mathrm{CuO}-\mathrm{H}_{2} \mathrm{O}$ nanofluid as compared to pure water for the same discharge rate due to increase in inertia forces. Figure 2 (b) shows the disparity of Nusselt number with volumetric flow rate. For the same volumetric flow rate, the Nusselt number value in $\mathrm{CuO}-\mathrm{H}_{2} \mathrm{O}$ nanofluid is more as compared to water. As a consequence, a significant increase in the rate of heat transfer is found.

$$
\begin{array}{ll}
f_{v}=V_{n p} / V_{n f} & V_{n p}=\text { quantity of nanoparticle, } \\
V_{n p}=W_{n p} / \rho_{n p}, & V_{b f}=\text { quantity of base fluid, } \\
V_{n f}=V_{n p}+V_{b f}, & V_{n f}=\text { quantity of nanofluid }
\end{array}
$$

\section{EXPERIMENTAL RESULTS}

$$
\begin{aligned}
& \operatorname{Re}=\frac{\rho V D}{\mu} \\
& N u=0.74 \operatorname{Re}^{0.707} \operatorname{Pr}^{-0.385} \phi^{0.07}, \\
& P e=\frac{V D}{\alpha}, \alpha=\frac{k}{\rho c_{p}}
\end{aligned}
$$
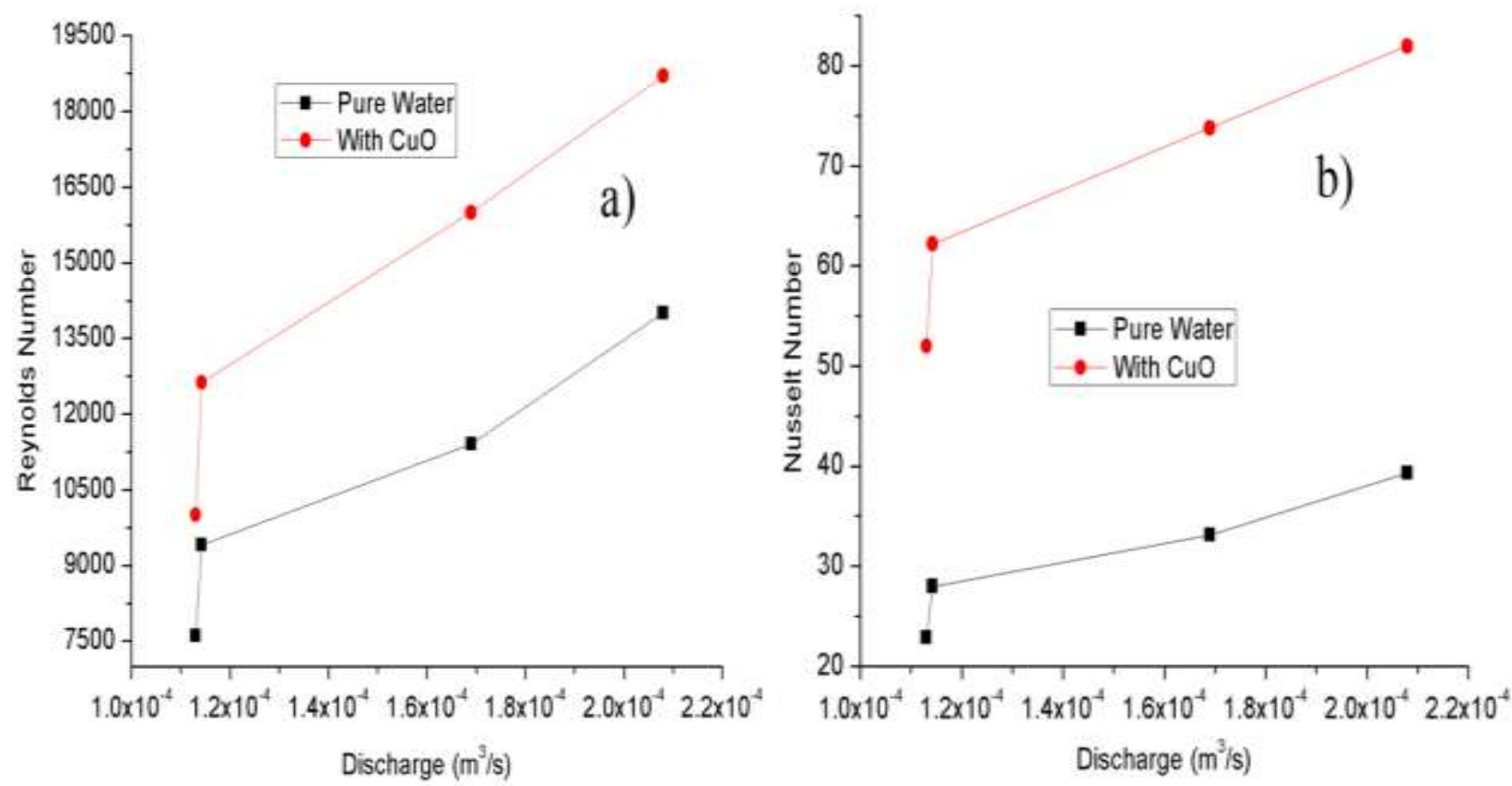

Fig-1: Variationof (a) ReynoldsNumber and (b) Nusselt Number withDischarge for Pure water and $\mathrm{CuO}-\mathrm{H}_{2} \mathrm{O}$ 

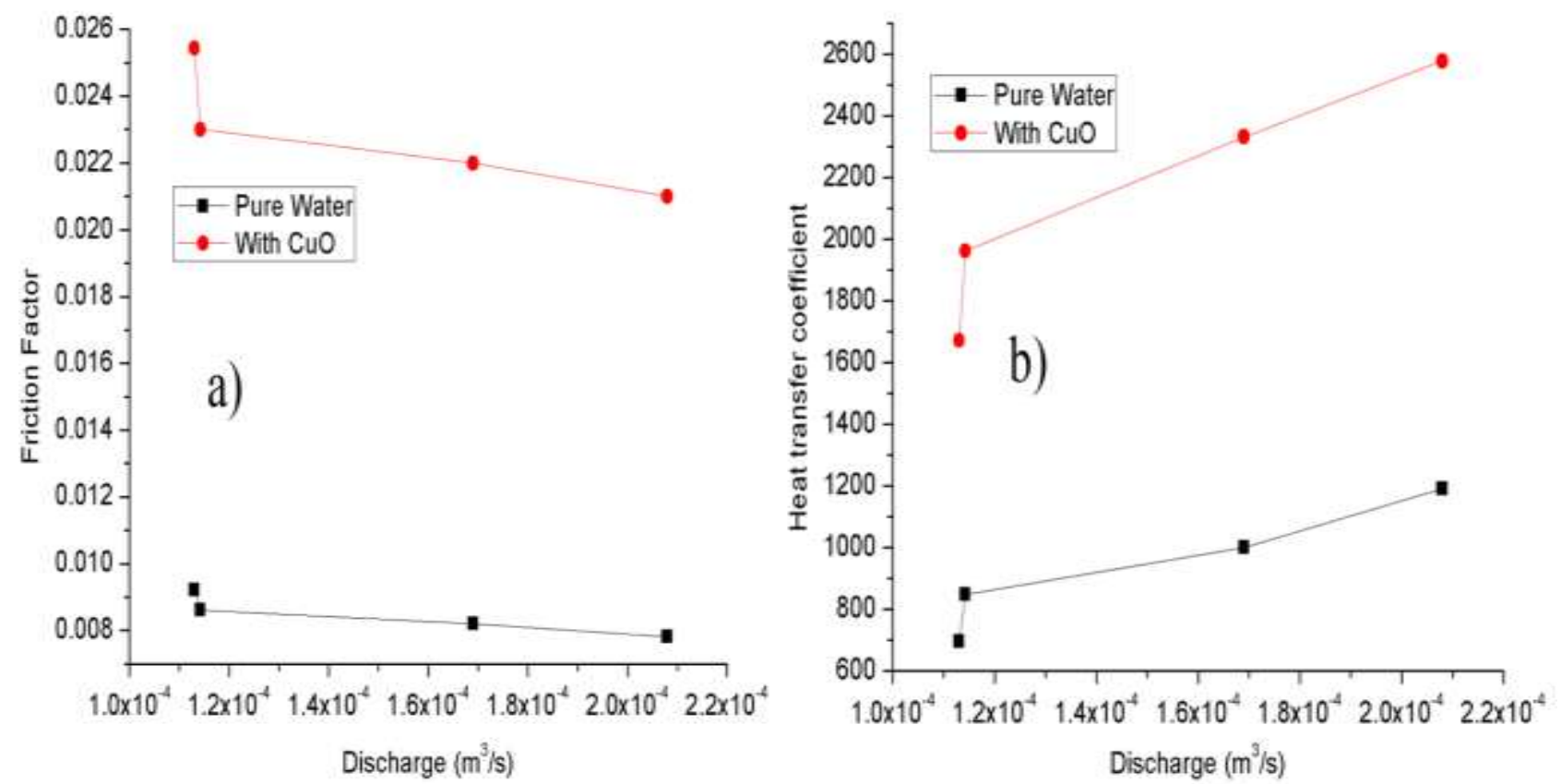

Fig-2: Variation of (a) Friction Factor (b) Heat Transfer Coefficient $\mathrm{h}\left(\mathrm{W} / \mathrm{m}^{2} \mathrm{~K}\right)$ with Discharge for Pure water and $\mathrm{CuO}-\mathrm{H}_{2} \mathrm{O}$
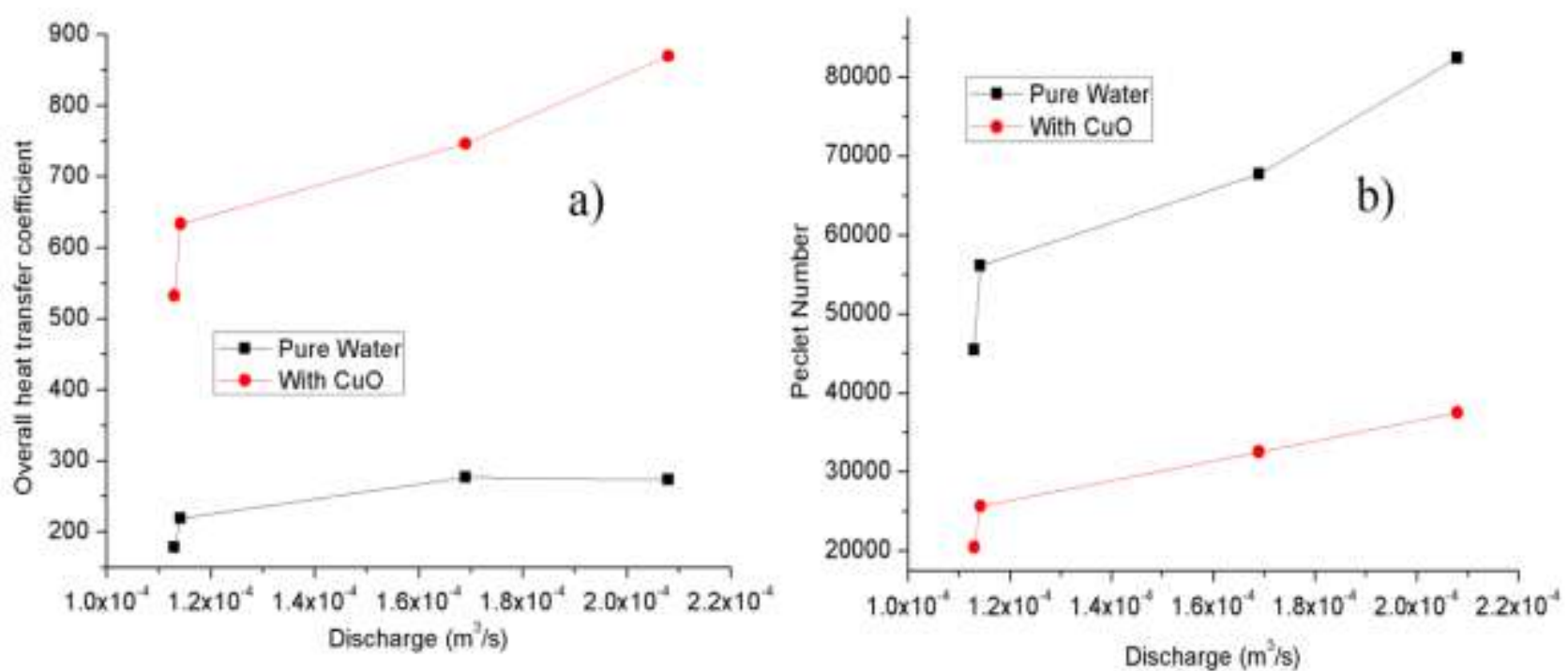

Fig-3: Variation of (a) Overall heat transfer coefficient and (b) Peclet Number withDischarge for Pure water and $\mathrm{CuO}_{-} \mathrm{H}_{2} \mathrm{O}$

$\operatorname{Pr}=\frac{\mu c_{p}}{k}$

$f=0.961 R e^{-0.375} \phi^{0.052}, h=\frac{N u * k}{D}$

Overall Heat Transfer Coefficient, $U=\frac{Q}{A \Delta T_{m}}$

where $\Delta T_{m}$ is Logarithmic MeanTemperature

Difference
Figure 3 (a) represents the variation in friction factor as a corollary of volume flow rate. From the figure, it can be concluded that there is a significant decrease in friction factor as volume flow rate increases. For a constant volume flow rate, the friction factor is found to be more in $\mathrm{CuO}$ $\mathrm{H}_{2} \mathrm{O}$ nanofluid as compared to water. Figure 3 (b) represents the change in heat transfer coefficient with respect to volumetric flow rate. Keeping same volumetric flow rate, it can be inferred that the heat transfer coefficient for $\mathrm{CuO}$ $\mathrm{H}_{2} \mathrm{O}$ nanofluid is more in comparison to water. This enhancement is due to superior thermophysical properties of nanofluids. 
Figure 4 (a) shows the contrast of overall heat transfer coefficient $\mathrm{U}\left(\mathrm{W} / \mathrm{m}^{2} \mathrm{~K}\right)$ with volume flow rate. From the figure, we can closure that $\mathrm{U}$ for $\mathrm{CuO}-\mathrm{H}_{2} \mathrm{O}$ Nanofluid is more as compared to water for the same volume flow rate. Therefore Nanofluids increase the thermal effectiveness of heat exchangers.Figure 4 (b) represents the variation of Peclet number with volume flow rate. It can be seen from the figure that for the same volume flow rate, the Peclet number for $\mathrm{CuO}-\mathrm{H}_{2} \mathrm{O}$ nanofluid is less as compared to water. This is because the thermal conductivity of Nanofluids is more, due to which conduction prevails as compared to convection.

\section{CONCLUSION}

Addition of $\mathrm{CuO}$ Nanoparticle results in the enhancement of the convective heat transfer coefficient, $h\left(W / \mathrm{m}^{2} \mathrm{~K}\right)$. It can also be seen that the Reynolds number found to increase when $\mathrm{CuO}$ Nanoparticles are added in the base fluid which increases the inertia forces. With the addition of nanoparticles in base fluid, the effect of pressure drop increases which increase pumping power. Therefore, such nanoparticles can be employed in the cooling applications efficiently at the expense of pumping power.

\section{REFERENCES}

[1] S. U. S. Choi and J. A. Eastman, "Enhancing thermal conductivity of fluids with nanoparticles," ASME Int. Mech. Eng. Congr. Expo, vol. 66, no. January 1995, pp. 99-105, 1995.

[2] B. H. Chun, H. U. Kang, and S. H. Kim, "Effect of alumina nanoparticles in the fluid on heat transfer in double-pipe heat exchanger system," Korean $J$. Chem. Eng., vol. 25, no. 5, pp. 966-971, 2008.

[3] W. Daungthongsuk and S. Wongwises, "A critical review of convective heat transfer of nanofluids," Renew. Sustain. Energy Rev., vol. 11, no. 5, pp. 797817, 2007.

[4] M. Goodarzi et al., "Investigation of heat transfer and pressure drop of a counter flow corrugated plate heat exchanger using MWCNT based nanofluids," Int. Commun. Heat Mass Transf., vol. 66, pp. 172-179, 2015.

[5] A. A. R. Darzi, M. Farhadi, K. Sedighi, R. Shafaghat, and K. Zabihi, "Experimental investigation of turbulent heat transfer and flow characteristics of $\mathrm{SiO} 2 /$ water nanofluid within helically corrugated tubes," Int. Commun. Heat Mass Transf., vol. 39, no. 9, pp. 1425-1434, 2012.

[6] A. Zamzamian, S. N. Oskouie, A. Doosthoseini, A. Joneidi, and M. Pazouki, "Experimental investigation of forced convective heat transfer coefficient in nanofluids of $\mathrm{Al} 2 \mathrm{O} 3 / \mathrm{EG}$ and $\mathrm{CuO} / \mathrm{EG}$ in a double pipe and plate heat exchangers under turbulent flow," Exp. Therm. Fluid Sci., vol. 35, no. 3, pp. 495-502, 2011.

[7] M. Chandrasekar, S. Suresh, and A. Chandra Bose, "Experimental investigations and theoretical determination of thermal conductivity and viscosity of Al2O3/water nanofluid," Exp. Therm. Fluid Sci., vol. 34, no. 2, pp. 210-216, 2010.

[8] L. Godson, B. Raja, D. Mohan Lal \& S. Wongwises, " Experimental Investigation on the Thermal Conductivity and Viscosity of Silver-Deionized Water Nanofluid," Experimental Heat Transfer: A Journal of Thermal Energy Generation, Transport, Storage, and Conversion, vol. 23, no 4, pp. 317-332, 2010.

[9] M. Jalal, H. Meisami, and M. Pouyagohar, "Investigation of titania/water nanofluid viscosity, density and pressure drop in a circular channel," World Appl. Sci. J., vol. 27, no. 8, pp. 1037-1041, 2013.

[10] S.Pethkool, S.Eiamsa-ard, S.Kwankaomeng, and P.Promvonge, "Turbulent heat transfer enhancement in a heat exchanger using the helically corrugated tube," Int. Commun. Heat Mass Transf., vol. 38, no. 3, pp. 340-347, 2011. 